\title{
Control of trainingloads through perceived exertion. Prediction of heart rate Control de las cargas de entrenamiento a través de la percepción subjetiva. Predicción de la frecuencia cardiaca \\ *Victor Murillo Lorente, *Javier Álvarez Medina, *Pedro Manomelles Marqueta \\ *Universidad de Zaragoza (España), **Universidad Católica de Murcia
}

\begin{abstract}
Objective: To use the perceived exertion to control training loads and to predict indirectly the heart rate without the need for monitoring the player. Methods: Nine futsal Spanish players were included in the study. All were monitored for a minimum of 25 sessions during the season. Subjective perception of exertion was assessed daily using Borg's RPE scale. Results: The mean heart rate was 138 beats per minute (bpm), with a minimum value of $75.2 \%$ of the maximum heart rate, which is equivalent to 15 («hard») on the RPE scale and to a mean value of perceived exertion of 15.06 \pm 2.01 . Individual values indicate that there are players whose perceived exertion is above, below or consistent with their heart rate. The results obtained differentiate four training session groups according to the players' heart rate values and perceived exertion. We used these results to develop a formula for predicting heart rate without monitoring the player. Conclusion: Player's perceived exertion is not always consistent with their cardiovascular response. This demonstrates that training loads are not only perceived from the physiological perspective, but also from a psychological point of view.
\end{abstract}

Keywords. futsal, control, training load, subjective perception, heart rate.

Resumen. Objetivo: Usar el esfuerzo percibido para controlar las cargas de entrenamiento y para predecir de forma indirecta el ritmo cardíaco sin la necesidad de supervisar el jugador. Métodos: Nueve jugadores españoles de fútbol sala fueron incluidos en el estudio. Todos fueron monitoreados durante un mínimo de 25 sesiones durante la temporada. La percepción subjetiva de esfuerzo fue evaluada diariamente utilizando la escala RPE de Borg. Resultados: La frecuencia cardíaca media fue de 138 latidos por minuto (lpm), con un valor mínimo de 75,2\% de la frecuencia cardiaca máxima, lo que equivale a 15 («duro») en la escala RPE y para un valor medio de esfuerzo percibido de 15,06 $\pm 2,01$. Los valores individuales indican que hay jugadores que percibe el esfuerzo está por encima, por debajo o en consonancia con su ritmo cardíaco. Los resultados obtenidos se diferencian cuatro tipos de sesión de entrenamiento de acuerdo a los valores de la frecuencia cardíaca de los jugadores y el esfuerzo percibido. Utilizamos estos resultados para desarrollar una fórmula para predecir la frecuencia cardiaca sin la supervisión del jugador. Conclusión: El esfuerzo percibido del jugador no siempre es coherente con su respuesta cardiovascular. Esto demuestra que las cargas de entrenamiento no sólo se perciben desde la perspectiva fisiológica, sino también desde un punto de vista psicológico.

Palabras clave. fútbol sala, control, carga de entrenamiento, percepción subjetiva, frecuencia cardiaca.

\section{Introduction}

According to Martín (2000), internal load intensity has a major impact on the performance of team-sports players especially the psycho-physiological aspects. These aspects are very hard to control and measure and they are often used to explain the relationship between organic processes and player's behavior. Internal load can be controlled using both, quantitative methods -such as heart rate monitoring-and qualitative methods -such as perceived exertion assessment using Borg's RPE (rate of perceived exertion) 15-score scale (Borg, 1962). Both variables have been extensively proven to be correlated, as reported in the review performed by Pandolf (Borg, 1962) and other more recent studies (Cuadrado, 2011; Kouidi, Kotzamanídís, Kellis, Kouitzidou, \& Deligiannis, 2000; Foster, Heimann, Esten, Brice, \& Porcari, 2001; Martín \& Andersen, 2000), and it is widely used in the prescription of exercise. In fact, Borg's formula for calculating heart rate according to the RPE(Borg, 1970) $(F C=$ RPE $x$ 10) is based on the correlation between perceived exertion and heart rate.

In general terms, the literature available on the correlation between RPE and HR establishes that there is a linear relationship between these two variables in most population groups and RPE can be considered a rough indicator of HR. Finding that RPE and HR are correlated has led researchers conclude that RPE is a good indicator of exercise intensity, since HR has traditionally been accepted as a valid indicator of exercise intensity (Serratosa, López, Legido, Vaquero, Calvo, \& Álvarez, 1992; Galy et al., 2014; Williams \& Eston, 1989). However, some studies have demonstrated that RPE can be as useful as or even more useful than HR to assess work loads (Williams \& Eston, 1989; Carton \& Rodhes, 1985; Noble, 1882; Chirosa

Fecha recepción: 05-09-15. Fecha de aceptación: 05-04-16 Victor Murillo Lorente

victormurillo1301@hotmail.com
LJ, Chirosa IJ, Feriche, Vallejo, \& Gómez, 2001; Glass, Knowlton, \& Becque, 1992; Eston, Davies, \& Williams, 1987).

Spiering, Wilson, Judelson, and Rundell (2003), in a study performed with hockey players, highlighted the need to develop a method for controlling training loads by calculating maximal HR, since pulsimeters -although affordable for most teamsare a nuisance during training and are not allowed in competition. Therefore, the possibility of using such a simple tool as a RPE scale to calculate HR is very promising. Actually, RPE could be used alone without employing any other invasive methods.

Objective: Using the perceived exertion to control training loads and to predict of indirect form the heart rate without the need for monitoring the player.

\section{Methods}

\section{Study Design}

An observational, longitudinal, repeated-measures 40-week study including 225 training sessions.

The method employed was approved by the Ethics Committee of the University of Zaragoza, Spain, according to the guidelines of the Declaration of Helsinki regarding human experimentation, which was approved in 1974 and modified in 2008. Informed consent was obtained from all players. Participants were free to withdraw from the study at any time.

\section{Participants}

The study included players from the first team of «Hormigoneras Umacón Zaragoza» of the Spanish Futsal League First Divison ( $\mathrm{n}=\mathrm{nine}$ ).

The characteristics of the sample were: age $27.00 \pm 5.12$ years; height $1.75 \pm .094 \mathrm{~m}$; weight $73.97 \pm 6.13 \mathrm{~kg}$.

Inclusion criteria were; be player of the first team or youth team and always go to training, except punctual causes of injury or disease. And the exclusion criteria; not always go to training, players with long term injuries and players who did not complete at least100 seasons. 
The nine subjects had participated the previous season in a pilot study. The timing was:

Season 2010 / 2011. Pilot study

- August to December 2010: PSE method was introduced to determine whether its implementation, was viable.

- January to May 2011: Having noted the usefulness of it and got good awareness of their use by the players began to control heart rate and compare the results.

Season 2011 / 2012. Full implementation of the tools. All participating players knew how to use the tool.

\section{Data Collection}

Maximum heart rate (HRmax) was obtained through a stress test. The test validated in previous studies, was conducted on a treadmill with a gradual continuous slope protocol fixed at $3 \%$ and increased load of $1 \mathrm{~km} . \mathrm{h}-1$ every minute. Ventilatory flow and expired gases were analyzed breath by breath (CPX Medical Graphics / MAX, St. Paul, Minnesota, USA)

In all training sessions four players were monitored using four Polar S725X Wearlink pulsimeters. All players were monitored for a minimum of 25 training sessions throughout the season, where different training modalities were employed. To facilitate data analysis, the players registered the laps at rest periods between exercises, series or repetitions. All HR files were entered into a database using Polar Irda Usb and Polar Pro Trainer 5 software. In accordance with Owen, Wong, McKenna and Dellal (2011) method, once the mean HR was calculated, we suppressed the HR values registered by the players and the coaching team during rest periods. This was the only way to obtain the mean HR during real work and eliminate any potential distorting values. Then we calculated the relative values for each player using the HRmax obtained in the stress test.

The use of heart rate monitors was determined by order list because only given four heart rate monitors. For future research it would be advisable to use a heart rate monitor for each player in all training sessions to have all the data and avoid other results in different sessions.

Players were asked to keep a daily RPE log to record player's RPE. RPEs were calculated using the RPE scale (Borg, 1962) (figure 1)

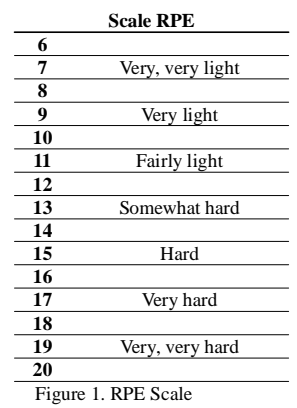

In all sessions each player stuffed his sheet individually. Players recorded their RPE ten minutes after finishing the training (Borg, 1962). Absolute and relative HR values were compared with RPE values using Buceta's table (Buceta, 1998) (table 1).

RPE values could be directly compared with absolute mean HR values, as they were obtained using the 15-point RPE scale. To compare RPE values with the relative proportion of the maximal HR (\%HRmax) we used the equivalence proposed by Bucet, since percentages ranged zero to 100 , and these values were related with the $C R-10$ scale (Borg, 1982).

\section{Training methods}

HR and RPE values were obtained in all sessions where the player was monitored. Unlike most studies (Makaje, Ruangthai, Arkarapanthu , Yoopat, 2012; Baroni, \& Leal Junior, 2010) -
Table 1.

Equivalence between PSE scales, FC and\% intensity. Buceta (1998).

\begin{tabular}{|c|c|c|c|}
\hline $\begin{array}{c}\text { Scale of Perceived } \\
\text { Exertion Borg 6-20 } \\
\text { points }\end{array}$ & $\begin{array}{c}\text { Approximate } \\
\text { equivalent in beats } \\
\text { per minute }\end{array}$ & $\begin{array}{c}\text { Degree of stress } \\
\text { intensity (\% of } \\
\text { maximum capacity) }\end{array}$ & $\begin{array}{c}\text { Equivalence Scale } \\
\text { of Perceived } \\
\text { Exertion Borg 0-10 } \\
\text { points }\end{array}$ \\
\hline 6 & $60-70$ & \multirow{2}{*}{10} & 0 \\
\hline Very, very light & $70-90$ & & 1 \\
\hline 8 & $80-100$ & \multirow{2}{*}{20} & \multirow{2}{*}{2} \\
\hline Very light & $90-110$ & & \\
\hline 10 & $100-120$ & \multirow{2}{*}{30} & \multirow{2}{*}{3} \\
\hline Fairly light & $110-130$ & & \\
\hline 12 & $120-140$ & 40 & 4 \\
\hline Somewhat hard & $130-150$ & 50 & 5 \\
\hline 14 & $140-160$ & 60 & 6 \\
\hline Hard & $150-170$ & \multirow{2}{*}{70} & \multirow{2}{*}{7} \\
\hline 16 & $160-180$ & & \\
\hline Very hard & $170-190$ & 80 & 8 \\
\hline 18 & $180-200$ & 90 & 9 \\
\hline Very, very hard & $190-210$ & 100 & 10 \\
\hline 20 & $200-220$ & & \\
\hline
\end{tabular}

which only recorded values during competition- we recorded values in five sessions of each training modality. Following Alvarez et al. (2001), we believe in collective and because of the need for tough, strong and quick players is necessary to insert specific sports situations purely physical character exercises during the preseason and in season, often by work mixed in which both types of work are combined mainly with the aim of improving individual weaknesses and get in the best possible conditions to the real match situations. They have distinguished five methods of training, which will work separately in each session:

- Anaerobic: cardiovascular work performed in sprint series + explosive force work.

- Aerobic: cardiovascular work performed in long, mediumintensity running series + resistance force work.

- Alactic: specific shooting situations and track speed.

- Specific: game situations similar to those in competition.

- Combined: cardiovascular work on track (fractional or changes of pace) + game situations

\section{Statistical analysis}

Descriptive and inferential statistical analysis of the different variables was performed using the SPS, version 19, software package (Licence property of the University of Zaragoza) and Excel (data analysis).

Descriptive statistical analysis was performed to analyze quantitative variables, means and standard deviation.

Pearson's $\mathrm{r}$ was used to calculate correlations and linear dependence between quantitative variables when linear regression conditions were satisfied.

In all cases, the level of significance was established at $p=$ .05. The Spearman rank correlation coefficient ( $r$ ) is given when the correlation was significant.

\section{Results}

The stress test (CPX Medical Graphics / MAX, St. Paul, Minnesota, USA) performed at the laboratory provided the HRmax of each player. The highest max HR was that obtained for player three (198 bpm), while the lowest was that for player one (172 bpm), which represents a $26 \mathrm{bpm}$ difference. The mean HRmax of the team was $185.22 \pm 7.72 \mathrm{bpm}$.

The highest mean HRmax was that obtained for player eight (155.9 bpm), while the lowest was that for player one (113.9 bpm), which represents a $42 \mathrm{bpm}$ difference. The mean HR of the team was $138.02 \mathrm{bpm}$.

The highest \%HRmax was that obtained for player eight (85.6\%) while the lowest was that for player seven (68.4\%). The mean for the team was $75.2 \%$.

Mean values for the team were 138.02 («somewhat hard»), 
Table 2.

Age, HRmax, HRA, \% HRmax, equivalence (Buceta, 1998), PSE and PSE-correlation\% HRmax each player and team.

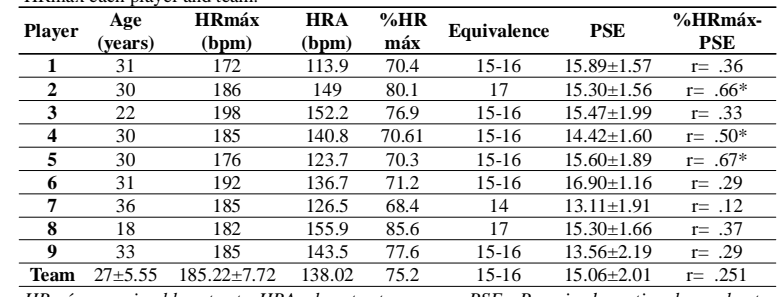

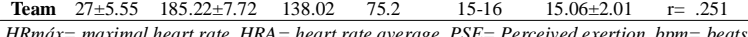
per minute

Table 3

PSE and \% HRmax in training each player as training method.

\begin{tabular}{|c|c|c|c|c|c|c|}
\hline & & Anaerobic & Aerobic & Alactic & Specific & Combined \\
\hline \multirow{2}{*}{ Player 1} & \%HRmax & $78.35 \%$ & $60.02 \%$ & $69.19 \%$ & $70.93 \%$ & $77.62 \%$ \\
\hline & PSE & $16.25 \pm .50$ & $13.36 \pm 3.07$ & $15.80 \pm .86$ & $16.05 \pm 1.24$ & $16.53 \pm .92$ \\
\hline \multirow{2}{*}{ Player 2} & \%HRmax & $76.81 \%$ & $56.96 \%$ & $74.92 \%$ & $80.36 \%$ & $84.76 \%$ \\
\hline & PSE & $16.40 \pm .55$ & $13.15 \pm 2.12$ & $14.57 \pm 1.22$ & $14.35 \pm 1.72$ & $16.00 \pm 1.27$ \\
\hline \multirow{2}{*}{ Player 3} & $\% \mathrm{HRr}$ & 77.39 & & & & \\
\hline & PSE & $15.33 \pm 1.53$ & $13.08 \pm 2.90$ & $15.19 \pm 1.64$ & $15.57 \pm 1.52$ & $16.82 \pm 1.67$ \\
\hline \multirow[b]{2}{*}{ Player 4} & \%HRmax & $73.50 \%$ & $78.63 \%$ & $67.40 \%$ & & \\
\hline & PSE & $13.00 \pm 1.15$ & 11.25 & $13.47 \pm 2.03$ & 14.91 & $15.59 \pm 1.73$ \\
\hline \multirow{2}{*}{ Player 5} & \%HRmax & $75.03 \%$ & 61. & 67.6 & 69 . & 80 \\
\hline & PSE & $16.25 \pm 1.71$ & $12.69 \pm 2.93$ & $15.44 \pm 1.50$ & $15.10 \pm 1.55$ & $17.12 \pm 2.00$ \\
\hline \multirow{2}{*}{ Player 6} & \%HRmax & $75.09 \%$ & $54.95 \%$ & $64.98 \%$ & $75.36 \%$ & $75.37 \%$ \\
\hline & PSE & $17.40 \pm 1.14$ & 15.00 & 16.13 & 17.0 & $17.56 \pm 0.73$ \\
\hline \multirow{2}{*}{ Player 7} & $\%$ HRmax & $65.14 \%$ & $65.04 \%$ & $64.49 \%$ & $71.59 \%$ & $75.07 \%$ \\
\hline & PSE & $14.67 \pm 2.52$ & $11.38 \pm 3.07$ & $13.46 \pm 1.98$ & $12.47 \pm 1.91$ & 14.94 \\
\hline \multirow{2}{*}{ Player 8} & \%HRmax & 83.10 & 72.8 & 84.56 & 84. & 90. \\
\hline & PSE & $15.50 \pm 1.00$ & 11.83 & $15.88 \pm 1.89$ & 15.14 & 16.7 \\
\hline \multirow{2}{*}{ Player 9} & \%HRmax & $72.86 \%$ & $62.76 \%$ & $77.53 \%$ & $81.55 \%$ & $84.27 \%$ \\
\hline & PSE & $14.50 \pm 3.54$ & 11.01 & $14.00 \pm 1.60$ & $13.65 \pm 1.62$ & $13.50 \pm 1.38$ \\
\hline \multirow{2}{*}{ Team } & \%HRmax & $75.07 \%$ & $65.43 \%$ & $70.25 \%$ & $76.21 \%$ & $80.55 \%$ \\
\hline & PSE & $15.48 \pm .95$ & & $99 \pm 1.02$ & $15.07 \pm 1.02$ & $16.08 \pm 1.03$ \\
\hline
\end{tabular}

Table 4.

\begin{tabular}{|c|c|c|}
\hline Player & Form & \%HRmax-PSE \\
\hline 1 & HRA $=50.369+4.706 \times$ PSE & $\mathrm{r}=.36$ \\
\hline 2 & HRA $=60.870+5.759 \times$ PSE & $r=.66^{*}$ \\
\hline 3 & $\mathrm{HRA}=102.387+3.369 \times \mathrm{PSE}$ & $\mathrm{r}=.33$ \\
\hline 4 & HRA $=88.305+3.638 \times$ PSE & $\mathrm{r}=.50^{*}$ \\
\hline 5 & $\mathrm{HRA}=47.765+4.867 \times \mathrm{PSE}$ & $r=.67 *$ \\
\hline 6 & HRA $=79.403+3.389 \times$ PSE & $\mathrm{r}=.29$ \\
\hline 7 & HRA $=91.042+2.395 \times$ PSE & $r=.12$ \\
\hline 8 & $\mathrm{HRA}=133.004+1.494 \times \mathrm{PSE}$ & $r=.37$ \\
\hline 9 & $\mathrm{HRA}=27.858+7.976 \times \mathrm{PSE}$ & $r=.29$ \\
\hline Team & $\mathrm{HRA}=87.234+3.475 \times$ PSE & $r=.251$ \\
\hline
\end{tabular}

TRá $=$ maximal heart rate, $H R A=$ heart rate average, $P S E=$ Perceived exertion

a \%HRmax of 75.2m, which corresponds to 15-16 («hard»), and a RPE of 15.06 \pm 2.01 («hard»). The correlation between \%HRmax and RPE of the team was $r=.251$ (table 2).

It is to be noticed that the highest mean values obtained for the team were those of cardiovascular response and RPE in combined sessions, with a \%HRmax of 80.55 and a RPE of $16.08 \pm 1.03$. The lowest values were those recorded in aerobic sessions, with a \%HRmax of $65.43 \%$ and a RPE of $12.72 \pm 2.36$ (table 3).

Table 4 shows the formulas employed to calculate the mean HR for each player and for the team. The non-significant correlations found between the \%HRmax and the RPE for players one, three, six, seven, eight and nine and the mean value obtained for the team will yield a low percentage of relationship for these cases (table 4).

\section{Discussion}

Relationship between absolute and relative $H R$ and $R P E$ values (table 2).

\section{Heart rate}

The results obtained show significant variability in absolute HRmax and mean HR values among players during training sessions, which is consistent with the results reported in previous studies. According to Jackson (2007) and Mora (2014), this variability is due to factors such as age, sports level, experience, motivation, and physical, technical and tactical aspects.

The mean HRmax for the team was $138.02 \pm 17.43 \mathrm{bpm}$.
Standard deviation shows that interindividual variability was higher as compared to that reported in other studies such as that performed by Álvarez et al.(2001). In his study, Alvarez reported a SD of $165 \pm 10 \mathrm{bpm}$, while Barbero-Álvarez JC, Soto, Barbero-Alvarez V, and Granda-Vera (2004) reported a much lower deviation: $172.9 \pm .8 \mathrm{bpm}$. This significant differences with the results obtained in our study are due to the fact that we recorded values both during training and during competition.

To minimize variability in absolute HR values, authors such as Gillach, Sallis, Buono, Patterson, and Nader (1989) have established that intra-personal intensity values should be always considered with respect to the HRmax of each player. Thus, the results obtained in this study with respect to the \%HRmax yielded a range between $68.39 \% \pm 4.97$ and $85.63 \% \pm 3.64$, which correspond to players seven and eight, respectively. Makaje et al. (2012) monitored 15 professional futsal players in two competition games and obtained a mean value of $89.8 \% \pm 5.8$. Baroni and Leal Junior(2010) followed-up 186 Brazilian firstdivision futsal players and obtained a mean value of $96.95 \% \pm 4.66$. These values are higher as compared to the values obtained in our study because they were recorded exclusively during competition games.

According to García (2005), the \%HRmax is essential to assessing individual exercise intensity, since the fact that two players show the same HR during training does not necessarily mean that they are working at the same intensity, as their HRmax may be different. In this case, we verified that:

Players with the same HRmax showed different percentages. That is the case of player four, with a HRmax of $185 \mathrm{bpm}$ and a \%HRmax of 76.10; and player seven, with a HRmax of 185 bpm and a \%HRmax of $68.39 \%$.

Players with the same percentage showed different HRmaxs. That is the case of player three, with a \%HRmax of 76.87 and a HRmax of $198 \mathrm{bpm}$, and player four, with a HRmax of 76.10 and a \%HRmax of $185 \mathrm{bpm}$.

\section{HR - intensity RPE. Team Values}

A mean HR of $138 \mathrm{bpm}$ is equivalent to a «somewhat hard» perception on the RPE scale; this value is below the relative values of 75.2 \%HRmax which, according to Buceta (1998), corresponds to 15 («hard») on the RPE scale and to RPE values of 15.06 \pm 2.01 . Muyor and López (2009) studied 59 amateur cyclists during an indoor cycling session and reported a RPE of $14.2 \pm 1.8$ («hard») and a mean HR of $145.1 \pm 12.8$. Relative HR values are not provided in that study. We did not find any study establishing a relationship between these variables throughout a season.

The existing correlation between \%HRmax and RPE was not significant $(r=.251)$ and was lower as compared to that reported in other studies such as that of Feriche, Chirosa LJ, and Chirosa IJ (2002), ( $r=.954)$ because the value provided is the mean for all players. It is worthy of note that Feriche et al. (2002) only recorded values in four handball training sessions.

If we relate the team's mean RPE value of $15.06 \pm 2.01$ with HR values using the formula proposed by Borg (1970) to calculate HR according to the RPE (HR = RPE x 10), we find a physiological strain of $150 \mathrm{bpm}$. These absolute values were within the range reported by Álvarez et al. (2002)-i.e. between 141 and $181 \mathrm{bpm}$ - for professional and amateur futsal players in competition. Burke and Collins (1984) suggest that 20 to 30 bpm should be added for RPEs 11 to 16 , since rest periods should be considered, given that they may reduce the perceived overall intensity. We did not apply this correction in our study, since we suppressed rest intervals before calculating the mean HR.

The mean RPE obtained and its relationship in absolute terms with high-intensity heart rates shows that the team's 
perception was consistent with the intensity of competition games, as established in previous studies.

\section{$H R$ - intensity RPE. Invididual Values}

Gillach et al. (1989) highlights the relevance of individual response, which is crucial for the study of RPE and HR. Gillach states that the relationship between RPE and HR should be assessed using relative values, taking individual values rather than absolute values as a reference.

Due to interindividual HR variability, it was necessary to identify cardiovascular response individually to relate it with the player's RPE. The mean HR, \%HRmax and RPE obtained revealed differences in players' perception:

- There were players who perceived exertion above what their HR reflected.

- There were players who perceived exertion below what their HR reflected.

- There were players whose perception matched what their HR reflected.

There were as many different responses as players.

- Players three and four showed the same values for the three variables, which corresponded to «hard».

- Players one and five showed values that corresponded to «hard» for all values except for the mean $\mathrm{HR}$, which value was below the other values. It is to be noticed that player one showed a mean HR of 113.9 -which corresponds to «light»- while his \%HRmax and RPE corresponded to «hard».

- Players two and eight showed a RPE below their \%HRmax.

- Players six and nine were the only to show a RPE that was not consistent with the values obtained for the other variables. Player six showed a higher RPE, which indicated that his perceived exertion was above what his physiological response indicated. The difference between his RPE (16.90土1.16) -»very hard»- and his mean HR (136.7) is remarkable. According to Wilmore et al. (2001), the fact that this player showed such a different response may be due to his different race, which might result in his assimilating physiological strain differently. Conversely, player nine showed a RPE below the other variables.

Individualized analysis allowed us to understand each player's response and determine if their physiological response was consistent with their perceived exertion. Pollock (1988) indicated that the most accurate way to establish the relationship between RPE and mean HR is by assessing it individually. This information can be very useful in interpreting individually the information yielded by the scale (Martin and Andersen, 2000). This study only analyzes the mean value for the whole season. However, the results obtained confirm that each player showed a different response. While some players showed a RPE well above the mean HR -player one (15.89 \pm 1.57 $>113.9)$, player five $(15.60 \pm 1.89>123.7)$ or player six $(16.90 \pm 1.16>136.7)$ - other players showed very similar values - player four $(14.42 \pm 1.60=140.8)$-, while other players showed values below the mean HR -player nine $(13.56 \pm 2.19<$ 143.5).

The results obtained reveal that players one, five and six shared a common characteristic: their mean HR was well below their RPE. Although their mean HR may seem very low with respect to the high value of perceived exertion, this is not true, since their HRmax is not been considered. The three players showed a \%HRmax slightly above seven (70.4\%, 70.3\% and $71.2 \%$, respectively), which, according to Buceta (1998) corresponds to a perception of «hard» on the six-20 scale. This demonstrates that absolute values do not reflect the actual intensity.

The \%HRmax-RPE correlation for each player -except for player seven-made the mean correlation coefficient of the team increase. Significant correlations were found between the \%HRmax and the perceived RPE in players two, four, and five.

\section{Individual HR and RPE values by training modality (table} 3)

Differences were found regarding relative values in some sessions, as it is the case of players three and eight in alactic sessions, where player three worked at $64.42 \%$ and player eight worked at $84.56 \%$. Similarly, differences were observed in players seven and eight in combined sessions, where player seven worked at $75.07 \%$ and player eight worked at $90.34 \%$.

Training modalities were classified according to the percentage of the HRmax they represented for the team. According to the contents of each session, five training modalities were identified:

- 80\% HRmax: Combined.

- 75\% HRmax: Anaerobic and specific.

- 70\% HRmax: Alactic.

- 65\% HRmax: Aerobic.

The results obtained according to the RPE showed four groups of differentiated training modalities:

- Very hard (16 and 17.9 score): Combined.

- Hard (14 and 15.9 score): Anaerobic, alactic and specific.

- Slightly hard (12 and 13.9 score): Aerobic.

Considering HR and RPE, the combined method was the modality with the highest intensity. Other studies (Arjol, 1997; Cuadrado, Chirosa LJ, Chirosa IJ, Martin, \& Aguilar, 2011) have demonstrated that this type of specific, integrated contents involves an almost maximal intensity.

Peres, Debora, and Del Campo (2011) report a RPE value of 10.71 for eight physical basketball sessions, a value below ours, which was $12.72 \pm 2.36$ in aerobic sessions and $15.48 \pm .95$ in anaerobic sessions. In specific sessions, Peres et al. report a value of 12.71 , which is also below our values, which were $14.99 \pm 1.02$ for alactic sessions, and $15.07 \pm 1.02$ for specific sessions. Del Campo (2004), in his study with 10 different basketball teams monitored for 21 sessions, reported values similar to those obtained in our study: 14 for specific training sessions and 13 for physical training sessions.

\section{RPE as an indirect method for predicting HR (table 4)}

(To find a common formula to all players should continue to research more subjects to confirm the utility)

We could predict the team's mean HR by calculating the correlation between \%HRmax and RPE. This correlation was calculated by linear regression according to the method employed by Steed et al.(1994) and by analyzing the mean values for the team and for each player. We developed the formula $(y=a+b x)$, which yields the theoretical mean HR of the team and of each player, being HR the dependent value and RPE the independent variable. Application conditions were verified in both cases.

HR and RPE correlation coefficients for each player were mostly below 0.50 and were not significant in some players, which means that the formula developed yields a low percentage of consistency. However, if we could improve correlation coefficients and enhance significance, the predictive value of the formula in individual and collective terms would also improve and the method would be enhanced.

This formula would allow coaching teams to control players' cardiovascular response individually and collectively immediately after a training session. Thus, objective results could be obtained simply by assessing the RPE, and players would not have to be monitored. In our opinion, if correlations were improved and the reliability of the predictive model was enhanced, we could make an important step forward in training control methods. 


\section{Conclusions}

HR and RPE are useful in high-level sports training and individual intensity control.

Player's perceived exertion is not always consistent with their cardiovascular response. This demonstrates that training loads are not only perceived from the physiological perspective, but also from a psychological point of view, which should always been taken into account.

Predicting heart rate through the subjective perception is a quick and effective manner without the need to monitor the athlete.

\section{Practical Implications}

The development of an accurate RPE-based formula would allow coaching teams to control training loads and obtain immediate information on the exercise intensity perceived by the player.

It is important to highlight the added value of this research and the experimental subjects are players in real situations of competition and training.

\section{Study limitations}

The study population in Spain is 16 teams located in different cities. So that the data are reliable and valid, must be collected using the same data collection procedure and by the same observer. This hinders the expansion of research.

\section{References}

Álvarez, J., Corona, P., Giménez, L., Serrano, E., \& Manonelles, P. (2001) Perfil cardiovascular en el fútbol-sala. Adaptaciones al esfuerzo. Arch Med Deporte, 18 (82), 143-148.

Arjol, J.L. (1997). Análisis sobre el uso de tareas integrales en el entrenamiento del fútbol de alta competición. Training Fútbol, 11, 18-26.

Barbero-Álvarez, J.C., Soto, V.M., Barbero-Álvarez, V., \& Granda-Vera, J. (2008). Match analysis and heart rate of futsal players during competition. J Sports Sci, 26 (1), 63-73.

Baroni, B.M., \& Leal Junior, E.C. (2010). Aerobic capacity of male profesional futsal players. J Sports Med Phys Fitness, 2010, 50 (4), 395-9.

Borg, G. (1982). A category scale with ratio properties for intermodal and interindividual comparisons. En: Geissler HG, Petzold P, editores. Psychophysical judgment and the process of perception. Deutscher Verlag der Wissenschaften, 25-34.

Borg, G. (1962). A simple rating scale for use in physical work test Fysiografiska Sdllskapets y Lund Forhandlingar, 32, 7-15.

Borg, G. (1970). Perceived exertion as an indicator of somatic stress. Scand J Rehab Med, 2 (3), 92-98.

Buceta, J.M. (1998). Psicología del entrenamiento deportivo. Madrid: Dykinson.

Burke, E.J., \& Collins, M.S. (1984). Using perceived exertion for the prescription of exercise in healthy adutls. En: Cantu RC, editor. Clinical Sports Medice Cantu. Lexington, Mass, Collamore press, 93-105.

Carton, R.L., Rhodes, E.C. (1985). A critical review of the literature on ratings scales for perceived exertion. Sports Med, 2, 198-222.

Chirosa, L.J., Chirosa, I.J., Feriche, B., Vallejo, L., \& Gómez, M. (2001). Validez del uso de la RPE en el control de la carga de entrenamiento en deportes colectivos. En: XI Congreso Internacional de la Federación Española de Medicina Deportiva. Oviedo.

Cuadrado, J., Chirosa, L.J., Chirosa, I.J., Martín, I., \& Aguilar, D. (2011). Estimación de la frecuencia cardiaca máxima individual en situaciones integradas de juego en deportes colectivos: Una propuesta práctica. Revista de Ciencias del Deporte, 7 (2), 91-99.

Cuadrado, J., \& Grimaldi, M. (2011). Medios para cuantificar la carga interna de entrenamiento en deportes de equipo. La frecuencia cardiaca, el consumo de oxígeno, la concentración de lactato en sangre y la percepción subjetiva del esfuerzo: una revisión. G-SE, 6, 99-101.

Del Campo, J. (2004). La intensidad del entrenamiento en jugadores de baloncesto medida a través de la percepción de esfuerzo y fatiga [Tesis doctoral]. Madrid: Universidad de Madrid, Departamento de Físicas e Instalaciones Aplicadas a la Edificación, al Medio Ambiente y al Urbanismo. E.T.S. Arquitectura.

Eston, R.G., Davies, B.L., \& Williams, J.G. (1987). Use of perceived effert ratings to control exercise intensity in young healthy adults. $J$ Appl Physiol, 56, 222-224.

Feriche, B., Chirosa, L.J., \& Chirosa, I.J. (2002). Validez del uso de la $\mathrm{RPE}$ en el control de la intensidad de entrenamiento en balonmano. Arch Med Deporte, 19 (91), 377-383.

Foster, C., Heimann, K.M., Esten, P.L., Brice, G., \& Porcari, J.P. (2001). Differences in Perceptions of Training by Coaches and Athletes. Sports Med, 8, 3-7.

Galy, O., Ben Zoubir, S., Hambli, M., Chaouachi, A., Hue, O., \& Chamari, K. (2104). Relationships between heart rate and physiological parameters of performance in top-level water polo players. Biol. Sport, 31, 33-38.

García, O. (2005). Estudio de la Frecuencia cardíaca del futbolista profesional en competición: un modelo explicativo a partir del contexto de la situación de juego. [Tesis Doctoral]. Universidad de La Coruña. Septiembre 2005

Gillach, M.C., Sallis, J.F., Buono, M.J., Patterson, P., \& Nader, P.R. (1989). The relationship between perceived exertion and heart rate in children and adults. Pediatr Exerc Sci, 1, 360-368.

Glass, S.C., Knowlton, R.G., \& Becque, M.D. (1992). Accuracy of RPE from graded exercise to establish, exercise training intensity. Med Sci Sports Exerc, 24, 1303-1307.

Jackson, A.S. (2007). Estimación de la frecuencia cardiaca máxima de la edad. ¿Es una relación lineal?. Med Sci Sports Exerc, 39 (5), 822-829.

Kouidi, E., Kotzamanídís, C., Kellis, S., Kouitzidou, C., \& Deligiannis, A. (2000). The effects of a year training on cardiorespiratory efficiency of soccer and handball greek players. Exerc Society Sport Sci, 24, 3035.

Makaje, N., Ruangthai, R., Arkarapanthu, U., \& Yoopat, P. (2012). Physiological demands and activity profiles during futsal match play according to competitive level. J Sports Med Phys Fitness, 52 (4), 336-74.

Martin, D.T., \& Andersen, M.B. (2000). Heart rate-perceived exertion relationship during training and taper. Sports Med, 40, 201-208.

Martín, R. (2000). La velocidad y la resistencia en los deportes de equipo. Training Futbol, 48, 34-39.

Mora Ferrera, J.C., Núñez Sánchez F.J., Martínez Cabrera, F.I., Rodríguez Sánchez P., \& Suárez Moreno-Arrones, L. (2014). Comparación de las demandas de carrera Fútbol7 vs. Fútbol1 en jugadores jóvenes de Fútbol. Retos. Nuevas tendencias en Educación Física, Deporte y Recreación, 26, 149-152.

Muyor, J.M., \& López, P.A. (2009). Respuesta de la frecuencia cardiaca y la percepción subjetiva del esfuerzo en principiantes, durante la práctica de ciclismo indoor. J Human Mov, 23, 49-57.

Noble, B.J. (1982). Chemical applications of perceived exertion. Med Sci Sports Exerc, 14, 406-411.

Owen, A., Wong, P., McKenna, M., \& Dellal, A. (2014). Heart rate responses and technical comparison between small-vs large sided games in elite professional soccer. J Strength Con Res, 25(8), 2104-10

Debora, K., \& Del Campo., J. (2011). Evaluación de la intensidad del entrenamiento de baloncesto a través del salto vertical y RPE. EFdeportes. Recuperado de: http://www.efdeportes.com/efd152/la-intensidad-del-entrenamiento-de-baloncesto.htm

Pollock, M.L. (1988). Prescribing Exercise for fitness and adherence. En Dishman RK, editor. Exercise Adherence: Ist Impact on Public Health. Champaing: Human Kinetics, 6, 259-277

Serratosa, L., López, J.L., Legido, J.C., Vaquero, A.F., Calvo, F., \& Álvarez, J. (1992). Percepción subjetiva del esfuerzo (RPE): reproductibilidad y relación con el umbral láctico. En: Congreso CCO 92. Málaga.

Spiering, B.A., Wilson, M.H., Judelson, D.A., \& Rundell, K.W. (2003). Evaluation of cardiovascular demands of game play and practice in women's ice hockey. J Strength Cond Res, 17 (2), 329-333.

Williams, J.G., \& Eston, R.G. (1989). Determination of the intensity dimension in vigorous exercise programmes with particular reference to the use of the rating of perceived exertion. Sports Med, 8, 177-189.

Wilmore, J., Stanforth, P., Gagnon, J., Rice, T., Mandel, S., \& Leon, A. (2001). Heart rate and blood pressure changes with endurance training: The heritage family study. Med Sci Sports Exerc, 33, 107-16. 